\title{
Research on Administrative Levels Adjustment Influencing Governmental Operation Cost
}

\author{
Yun $\mathrm{Wu}$ \\ School of Management \\ Capital Normal University \\ Beijing, China
}

\begin{abstract}
The administrative levels adjustment could be a path to reduce governmental operation cost. Thus the administrative levels adjustment reform should on the basis of theories of decentralized, matching management scope and level matching, matching power and responsibility, government function transformation and minimizing information uncertainty. Province governing county reform is the policy of administrative levels adjustment, which leads to changes of "resource" "power" and "process" in order to reduce of governmental operation cost.
\end{abstract}

Keywords-Administrative Levels Adjustment; Governmental Operation Cost; Province Governing County

\section{INTRODUCTION}

Nowadays, market mechanism and modernization run smoothly in China. Meanwhile, reform of administrative system has entered a crucial stage, in which the local administrative levels adjustment become a key area. This adjustment is not only important to the sustainable development of local economy and local government macrocontrol ability, but also important to reduce the operation governmental operation cost of local government.

System of city governing county, as the core of longitudinal relationship of local government system in our country, is being blamed for hindering the development of county economy, causing the county level financial sleepy and keep the operation governmental operation cost of local government high. After a series of policies to expanse the power of county, the longitudinal relations reform have made a breakthrough from the system, which change the city governing county system to the province governing county system. With the deepening of this reform, the change in the aspect of governmental operation cost gradually highlights.

\section{THEORETICAL ESTABLISHMENT OF ADMINISTRATIVE LEVELS ADJUSTMENT INFLUENCING GOVERNMENTAL OPERATION COST}

\section{A. Decentralization and Centralization}

Competition between different levels of government and different departments within the same level is conducive to public resource configuration optimization and beneficial to

Sponsor: Youth Philosophy and Social Sciences Research Innovation Team Project, "Municipal Community Governance" Research Team. the improvement of the efficiency of the government ${ }^{1}$.

On the one hand, decentralization may lower the liquidity of information and makes the cost signal display function into full play. But due to local protectionism, regional segmentation and tribal conflicts, decentralization may intensify social chaos and disorder which lead to the increase of administrative cost and coordination cost. So the decentralized system which minimize the administrative cost and coordination cost is the optimal decentralization system ${ }^{2}$.

On the other hand, although centralization avoid problem of local protectionism, it may counter problems of infringement of private property rights and cost signal failure. So the centralized system which minimize the administrative cost and coordination cost is the optimal centralization system.

\section{B. Management Scope and Management Level}

On the one hand, the number of levels of local government influences governmental operation cost. Firstly, from the perspective of political system, our country is centralized unitary state and the government at a lower level without authorization should turn to its superior for instructions. The lack of discretion makes county level government lacks the enthusiasm of saving governmental operation cost. Secondly, from the perspective of administrative procedure, more administrative levels lead to long procedure of examination and approval, more time and more governmental operation cost. Thirdly, from the perspective of government organizations, more employees means more cost. Fourthly, from the perspective of policy information, more administrative levels lead to slow speed of policy information transmission and worse distortion of information. Fifthly, from the perspective of public service behavior, more administrative levels contribute to more badly bureaucracy, eventually not conducive to the improvement of administrative efficiency.

On the other hand, the matching of management scope and management level influences governmental operation cost. Matching refers to in a certain population scale,

1 Geoffrey Brennan, James M. Buchanan. The Power to Tax: Analytical Foundations of a Fiscal Constitution. Cambridge[M]. UK: Cambridge University Press, 1980, p. 156.

2 A. Breton, A. Scott. The Economic Constitution of Federal States[M]. Toronto: University of Toronto Press, 1978, p. 135. 
regional scale and number of lower administrative agencies, information can rapidly and accurately communicate between different government levels, policy can conscientiously implemented between different government levels, and resources between various government levels can flow and share. There is a general rule which is large management scope matches few management levels while small management scope matches more management levels.

\section{Authority with Corresponding Responsibility}

According to "fiscal power separation theorem" 3 from Musgrave, longitudinally, segmentation of financial authority between different levels government decided governmental operation cost. Under certain conditions, when reach the optimal division of fiscal authority, local governments in the "Pareto Optimality" conditions meet the demand of public goods and public services within its jurisdiction. This time is the time to local government running cost minimum.

In addition, the reform of the administrative hierarchy division, also means that the horizontal power function transformation between government, market and society. From Europe and the United States government administrative levels change experience, when the social power and administrative power determine the government administrative level settings together, and when the boundaries between government and society clear enough, is the time to local government running cost minimum. If fail to meet this condition, even the government administrative levels reduced, the governmental operation cost would not reduce.

\section{Government Functions Transform}

From the perspective of the transformation of government function, the starting point and ending are not in governmental system itself, but in the relationship reconstruction between the government system and its external environment.

Based on the needs of the regional economic and social development, to solve the problems of county level government function dislocation, vacancy and offside, county level government should transform the functions down to public service, social governance, economic regulation and environment protection. First, the county level government is no longer playing the role as "paddle", but the role as "steersman". Secondly, to build a service-oriented government requirements the county level government make more use of advanced technology to save governmental operation cost.

\section{E. Uncertainty and Information Transmission}

In the typical bureaucratic organization, the path of information transmission is: policy decision and administrative command pass through from top to bottom, while realistic problems and policy recommendations pass through from bottom to top. Assume the higher government makes policy decision on the base of the description and

3 J. Martinez-Vazquez, R. M. Mcnab. Fiscal Decentralization and Economic Growth[J]. World Development, 2003, 31(9), pp. 1597-1616. policy suggestions from the government at a lower level, so the changes from description and policy suggestions may lead to changes of the policy decision. In the process of transmission, information may become inaccurate, due to the change of the reality itself or the passer's misunderstanding or preferences. "In a hierarchical organization without degradation and has more than two government employees, the information transmission must be non-neutral, namely biased". More government levels lead to longer time to pass policy information, bigger probability of practice change and more passers who would twist the true information inevitably. If information transmission cannot go smoothly, the government will not be efficient in decision-making and policy implementation, which will rise governmental operation cost.

\section{POLICY ANALYSIS OF ADMINISTRATIVE LEVELS ADJUSTMENT INFLUENCING GOVERNMENTAL OPERATION COST: Province Governing COUNTY}

The twelfth five-year plan for national economic and social development outline said: "further transform government functions, deepen the reform of the administrative examination and approval system... continue to optimize the structure of government, administrative levels, functions, responsibilities, reduce administrative cost.. explore province governing county system in the conditional province." Obviously, one of the goals of province governing county policy is to reduce governmental operation cost. Province governing county policy could reduce governmental operation cost by the paths of changing arrangement on resource, power and procedure between province, city and county.

\section{A. Changing Resource Arrangement}

Province governing county policy brings the change of arrangement on financial resources and administrative resources of local government. Before the reform, the provincial government took charge of allocation of financial resources and administrative resources in the jurisdiction, to municipal government directly. And then the municipal government took charge of allocation of financial resources and administrative resources in the jurisdiction, to county level government directly. But the county level government did not make any connection with the provincial government generally. After the reform, the provincial government uniformly allocates resources to the municipal government and the county level government.

This new arrangement avoids the drawbacks of the older arrangement for the municipal government to withhold or hinder resources that own to county level government. On the one hand, under the system of tax distribution, it ensures that the county level government can fully get the sharing from the provincial government, harvest fixed retention ratio and income increment sum returns. On the other hand, under the system of governing just down one level, it ensures that the county level government can fully get policy incentives, incentives and policies from the province.

4 A. W. Beggs. Queues and Hierarchies[J]. Review of Economics Studies, 2001, 68(235), pp. 297-322. 
In this case, the county level government has a tendency to reduce governmental operation cost. Because having more financial and administrative resources means that they can independently control and allocate these financial and administrative resources. They not only need no calculate and ague with municipal government for the resourced allocation, but also get full motivation to reduce governmental operation cost.

\section{B. Changing Longitudinal Fiscal Power Arrangement}

Province governing county policy brings the change of arrangement on longitudinal financial power of local government. Before the reform, generally the county level government did not make any connection with the provincial government and the municipal government played a role in transit financially. After the reform, systematic subsidies, tax return, fiscal transfer payment, special funds subsidies, financial settlement, the solution and scheduling, debt repayment all happen between the county level government and the provincial government, without the municipal government.

In this case, the county level government has a tendency to reduce governmental operation cost. Because the county level government has more financial power, which matches the need to deal with numerous important and fragmented tasks in county level. The perfect matching of financial power and duty leads to governmental operation cost savings. Besides, in the situation when county level governments get adequate fiscal transfer payment, special funds subsidies and so on, they gain financial independence and autonomy, which is helpful to reduce the governmental operation cost because of decision making process.

\section{Changing Longitudinal Administrative Power Arrangement}

Province governing county policy brings the change of arrangement on longitudinal administrative power of local government. Before the reform, generally the county level government did not make any connection with the provincial government and the municipal government played a role in transit administratively. After the reform, the county level governments own the approval authority of the development plan, the economic trade, land and resources, taxation, transportation, water conservancy, the personnel and tourism, without the direction from the municipal government.

In this case, the county level government has a tendency to reduce governmental operation cost. Because the county level government has more administrative power, which matches the need to deal with numerous important and fragmented tasks to manage economic and social affairs in county level. These public affairs happen and benefit or damage the interest of people in county. The county level government is close to these public affairs geographically and psychologically, and is familiar with practical situation. So let the county level government governs these public affairs itself not only avoid mistakes because of lack of practical situation, but also save medium actions between different levels of governments. Besides, county level governments get adequate independence and autonomy, which is helpful to reduce the governmental operation cost because of decision making process.

\section{Changing Administrative Procedure Arrangement}

Province governing county policy brings the change of arrangement on administrative procedure between local governments. Before the reform, the provincial government governs the municipal government and the municipal government govern the county level government administratively. After the reform, the provincial government governs the county level government without the medium role of municipal government.

In this case, the county level government has a tendency to reduce governmental operation cost. Shorten of the administrative processes is helpful to reduce governmental operation cost. Firstly, because the county level government could make decision itself no longer waiting for the instructions from the municipal government, the governmental operation cost would decline together with the reduce of time and spirit spent on the decision making process. Secondly, because information communicate between the provincial government and the county level government directly, the governmental operation cost would decline together with the faster speed of information transport and the better information veracity which means less possibility of distortion and distortion. Thirdly, the governmental operation cost would decline together with the disappear of cost for the county level government to receipt and host duplicating meetings.

\section{CONCLUSION AND DISCUSSION}

Reducing governmental operation cost is urgent to our country. At the same time, the administrative levels adjustment is the core to the administrative system reform of our country. In order to achieve the goal of local government operation cost reduced, the administrative levels adjustment should follow a way to reduce the levels of local government, supporting by theories of design of the optimal decentralized or centralized system, management scope and management level matching, power and responsibility matching, government function transformation, as well as minimizing information uncertainty. Province governing county policy is a reform policy to reduce the levels of local government. It leads to changes of "resource" "power" and "process", which means giving more financial and administrative resources to county level government, giving more financial and administrative power to county level government and to streamline administrative procedure, to reduce governmental operating cost.

\section{REFERENCES}

[1] Geoffrey Brennan, James M. Buchanan. The Power to Tax: Analytical Foundations of a Fiscal Constitution. Cambridge[M]. UK: Cambridge University Press, 1980, p. 156.

[2] A. Breton, A. Scott. The Economic Constitution of Federal States[M]. Toronto: University of Toronto Press, 1978, p. 135.

[3] J. Martinez-Vazquez, R. M. Mcnab. Fiscal Decentralization and Economic Growth[J]. World Development, 2003, 31(9), pp. 1597 1616. 
[4] A. W. Beggs. Queues and Hierarchies[J]. Review of Economics Studies, 2001, 68(235), pp. 297-322. 